\title{
A ESCOLARIZAÇÃO DE ALUNOS COM DEFICIÊNCIA INTELECTUAL SOB A VIGÊNCIA DA POLÍTICA NACIONAL DE EDUCAÇÃO ESPECIAL NA PERSPECTIVA DA EDUCAÇÃO INCLUSIVA ${ }^{1}$
}

\author{
LA ESCOLARIZACIÓN DE ALUMNOS CON DISCAPACIDAD \\ INTELECTUAL BAJO LA VIGENCIA DE LA POLÍTICA NACIONAL DE \\ EDUCACIÓN ESPECIAL EN LA PERSPECTIVA DE LA EDUCACIÓN \\ INCLUSIVA
}

\begin{abstract}
THE SCHOOLING OF STUDENTS WITH INTELLECTUAL DEFICIENCY UNDER THE NATIONAL POLICY OF SPECIAL EDUCATION IN THE PERSPECTIVE OF INCLUSIVE EDUCATION
\end{abstract}

Marcela Francis Costa LIMA ${ }^{2}$ Marcia Denise PLETSCH ${ }^{3}$

RESUMO: O artigo analisa a escolarização de alunos com deficiência intelectual sob a vigência da Política Nacional de Educação Especial na Perspectiva da Educação Inclusiva. A partir de um estudo qualitativo baseado na perspectiva histórico-cultural de Vigostki, discutimos as múltiplas dimensões da inclusão escolar tendo como foco os processos de mediação da aprendizagem desse alunado em classes comuns de ensino de escolas localizadas na Baixada Fluminense/RJ. Para coleta de dados utilizamos observação em sala de aula com registros em diário de campo e escala de envolvimento. A análise de dados evidenciou que o nível de envolvimento dos sujeitos com deficiência intelectual nas atividades propostas está inteiramente relacionado com as mediações pedagógicas direcionadas aos mesmos. Mostrou que a escolarização destes sujeitos teve avanços significativos a partir das políticas de inclusão escolar, mas que ainda existem inúmeras barreiras para superar a cultura da impossibilidade presente no discurso docente e na sociedade em geral.

PALAVRAS-CHAVE: Deficiência intelectual. Políticas de educação inclusiva. Mediação pedagógica.

RESUMEN: El artículo analiza la escolarización de alumnos con discapacidad intelectual bajo la vigencia de la Política Nacional de Educación Especial en la

\footnotetext{
${ }^{1} \mathrm{O}$ texto é fruto da dissertação de mestrado da primeira autora, orientada pela segunda autora, integrou uma pesquisa em rede financiada pelo Programa Observatório da Educação da Coordenação de Aperfeiçoamento de Pessoal de Nível Superior (CAPES), da Fundação de Amparo à Pesquisa do Estado do Rio de Janeiro (FAPERJ) e do Conselho Nacional de Desenvolvimento Científico e Tecnológico (CNPq). Protocolo do comitê de ética da UFRRJ número $272 / 2012$.

${ }^{2}$ Universidade Federal Rural do Rio de Janeiro (UFRRJ), Rio de Janeiro - RJ - Brasil. Professora substituta do Departamento de Educação e Sociedade. Doutoranda e Mestre em Educação pelo Programa de Pós-graduação em Educação, Contextos Contemporâneos e Demandas Populares (PPGEduc). Bolsista da FAPERJ. ORCID: <http://orcid.org/0000-0001-5274-4966>.E-mail: marcela.fcl@ gmail.com

${ }^{3}$ Universidade Federal Rural do Rio de Janeiro (UFRRJ), Rio de Janeiro - RJ - Brasil. Professora Associada do Departamento Educação e Sociedade e do PPGEduc, UFRRJ. Jovem Cientista do Nosso Estado da FAPERJ e Pesquisadora do CNPq. ORCID: <http://orcid.org/0000-0001-5906-0487>. E-mail: marciadenisepletsch@ gmail.com
}

RPGE- Revista on line de Política e Gestão Educacional, Araraquara, v. 22, n. esp. 2, p. 872-889 dez., 2018. E-ISSN:1519-9029. 
Perspectiva de la Educación Inclusiva. A partir de un estudio cualitativo basado en la perspectiva histórico-cultural de Vigostki, discutimos las múltiples dimensiones de la inclusión escolar teniendo como foco los procesos de mediación del aprendizaje de ese alumnado en clases comunes de enseñanza de escuelas ubicadas en la Baixada Fluminense/RJ. Como instrumentos de recolección de datos utilizamos la observación en las clases con registros en diario de campo y la escala de participación. El análisis de datos evidenció, entre otros resultados, que el nivel de participación de los sujetos con discapacidad intelectual en las actividades propuestas está intimamente relacionado con las mediaciones pedagógicas dirigidas a ellos. Asimismo mostró que la escolarización de estos sujetos tuvo avances significativos a partir de las políticas de inclusión escolar, pero que también existen todavía innumerables barreras para superar la cultura de la imposibilidad presente en el discurso docente y en la sociedad en general.

PALABRAS CLAVE: Discapacidad intelectual. Políticas de educación inclusiva. Mediación pedagógica.

ABSTRACT: This article analyzes the schooling of students with intellectual disabilities under the National Policy on Special Education in the perspective of Inclusive Education. From a qualitative study based on the historical-cultural perspective of Vigostki, we discuss the multiple dimensions of school inclusion focusing on the processes of mediation of learning of this student in common classes of schools located in the Baixada Fluminense/RJ. As data collection instruments we used classroom observation with field diary records and the scale of involvement. The dada analysis showed, among other results, that the level of involvement of subjects with intellectual disabilities in the proposed activities is entirely related to the pedagogical mediations directed to them. Likewise, it showed that the schooling of these subjects had significant advances from the policies of school inclusion, but that there are still many barriers to overcome the culture of impossibility present in the teaching discourse and in society in general.

KEYWORDS: Intellectual deficiency. Inclusive education policies. Pedagogical mediation.

\section{Introdução}

Nos últimos anos tem se ampliado as discussões em torno da política de educação inclusiva (BRASIL, 2008; 2009). Nesse contexto, reconhece-se cada vez mais a urgência de uma educação de qualidade para todos. Um dos temas mais discutidos nos últimos anos tem sido o processo de escolarização de pessoas com deficiências. Vale ressaltar que, historicamente, a educação das pessoas com deficiências, sobretudo nos casos mais severos, foi contraditoriamente pautada pela crença em sua ineducabilidade. Em que pesem as iniciativas anteriores, no Brasil, os debates sobre a educação inclusiva e suas dimensões políticas intensificaram-se, a partir dos anos 2000, especialmente a 
partir do Governo de Luiz Inácio Lula da Silva (2003-2010), período em que se elaborou a atual Politica Nacional de Educação Especial na Perspectiva da Educação Inclusiva (BRASIAL, 2008), atualmente em processo de revisão.

No caso da inclusão de alunos com deficiência intelectual em turmas comuns de ensino várias ainda são as barreiras descritas por diferentes autores (SOUZA, 2013; PADILHA, 2014; OLIVEIRA, 2014; OLIVEIRA, 2016; CAMPOS, 2016; SILVA, 2016; MENDES, 2016) para efetivar a sua plena participação e aprendizagem de conceitos científicos. Com a publicação da Política anteriormente mencionada e das Diretrizes do Atendimento Educacional Especializado na Educação Básica, modalidade de educação especial (BRASIL, 2009), esta questão tem recebido mais atenção nas discussões acadêmicas e políticas, pois foi a partir de sua implementação que o número de matrículas de alunos com deficiência intelectual se ampliou nas escolas públicas.

Como já apresentamos em outro artigo, a partir da análise dos microdados do INEP organizados por Rebelo (2016), no período de 2007 a 2014, o número de matriculas em classes e escolas especiais decresceu 46,0\% e aumentou $128,3 \%$ em classes comuns. As matrículas no Atendimento Educacional Especializado (AEE) também aumentaram 136,50\%. De acordo com a autora, o maior número de matrículas, assim como em outras épocas históricas, é de pessoas com deficiência intelectual, seguidas pela deficiência física, baixa visão, auditiva, surdez e cegueira. Ainda segundo os microdados, alunos com deficiência intelectual concentram o maior número de matrículas e somam, ao todo, cerca de $70 \%$ de todo o contingente de alunos públicoalvo da Educação Especial (MENDES, et al, 2016; PLETSCH et al, 2017).

Em que pesem os avanços, pesquisas recentes têm evidenciado que discussões sobre a aprendizagem de tais sujeitos ainda são escassas diante a demanda (MENDES, 2016). Dito isto, nos propomos a refletir sobre o processo de escolarização de sujeitos com deficiência intelectual matriculados nas redes comuns de ensino da Baixada Fluminense/RJ. Nosso foco será discutir e analisar o conceito de mediação pedagógica a partir das indicações da perspectiva histórico-cultural de Vigotski (2007, 2010, 2012). Também pretendemos trazer dados para refletir sobre as concepções docentes e o nível de envolvimento dos alunos com deficiência intelectual nas atividades escolares tomando como pano de fundo as propostas de educação inclusiva em vigência a partir de 2008 no Brasil. 


\section{Procedimentos metodológicos e referencial teórico}

Em termos metodológicos nos pautamos nos pressupostos da proposta qualitativa em dialogia com a perspectiva histórico-cultural, que foi o nosso referencial teórico. A pesquisa foi realizada em escolas localizadas na Baixada Fluminense/RJ, mais especificamente em sete redes de ensino: Nova Iguaçu, Duque de Caxias, Belford Roxo, Mesquita, Queimados, São João de Meriti e Nilópolis. A coleta de dados foi realizada nos anos de 2013 e inicio de 2017. Vale aqui mencionar que, este artigo, é fruto de uma pesquisa de mestrado que integrou um conjunto de estudos em rede colaborativa por três Programas de Pós-Graduação em Educação, a saber: UFRRJ, UDESC e UNIVALI. O projeto teve como foco analisar a escolarização e a avaliação de alunos com deficiência intelectual em 11 redes de ensino, das quais cinco no Estado de Santa Catarina e os sete do Estado do Rio de Janeiro mencionados anteriormente.

Como procedimentos empregamos os registros em diário de campo,,, a partir das observações em sala de aula comum de ensino e usamos como instrumento a Escala de Envolvimento. Essa escala foi traduzida e adaptada da escala original The Leuven Involvement Scale for Young Children (LIS-YC) (LEAVERS, 1994a). Para a aplicação da Escala de Envolvimento tivemos como base as pesquisas de Cathcart (2011), Silva (2016) e Mendes (2016), as quais foram pioneiras na adaptação e aplicação da mesma no Brasil. Segundo essas autoras, a referida escala é constituída por dois componentes: uma lista de indicadores/sinais, característicos de um comportamento de envolvimento, e os níveis de envolvimento numa escala de cinco pontos.

A lista de sinais de envolvimento da criança compreende nove indicadores, sejam eles: concentração; energia; complexidade e criatividade; expressão facial e postura; persistência; precisão; tempo de reação; comentários verbais e satisfação. Com base nestes sinais é que se pode identificar numa escala que vai de nível um a nível cinco, em qual dos níveis de envolvimento a criança se encontra quando está executando uma atividade (MENDES, 2016). Para descrever tais níveis novamente citamos Carthcart (2011), Mendes (2016) e Silva (2016): a) Nível 1 de envolvimento: ausência de atividade, que se evidencia quando a criança está inativa, sentada num canto, distraída e ausente; b) Nível 2 de envolvimento: atividade frequentemente interrompida é evidenciado quando a criança realiza as ações com uma ausência de consciência; c) Nível 3 de envolvimento: atividade mais ou menos contínua, a criança está mais ou menos empenhada continuamente na atividade, e esta é interrompida 
sempre que um estímulo interessante surge; d) Nível 4 de envolvimento: atividade com momentos intensos, a criança faz um grande esforço mental, quando a atividade é rotineira e importante para ela, levando a criança a permanecer concentrada durante a maior parte do tempo; e) Nível 5 de envolvimento: atividade intensa mantida é o envolvimento máximo da criança, quando ela está focalizada nas ações e no material e os estímulos circundantes não a distrai.

Assim como utilizado por Carthcart (2011), Mendes (2016) e Silva (2016), para a identificação dos níveis de envolvimento do aluno, foram utilizadas cores, para diferenciar os momentos de interação, sinais indicativos de envolvimento, e os momentos de mediação. Dessa forma, as cores utilizadas foram: a) azul para as falas e cenas que indicassem momento de mediação. Esse foi o foco central de análise da nossa pesquisa, saber em quais momentos houve mediação e se essa mediação foi de qualidade e proporcionou avanço no nível de envolvimento da criança na atividade; b) Laranja para as falas e cenas que indicassem o nível de envolvimento do aluno nas atividades propostas. Também pretendemos ter um foco de análise nesse quesito, para identificar como a mediação pode influenciar no envolvimento do aluno na atividade; c) Verdle para as falas e cenas que evidenciassem momentos de interação e os sinais de envolvimento que são base de análise dos níveis de envolvimento. Nesse caso iremos observar se existiu algum tipo de mediação entre os próprios alunos e analisar esse fato.

Em função da amplitude dos dados coletados, para este artigo focaremos, mesmo que sucintamente, aqueles que dizem respeito a dois sujeitos ${ }^{4}$ : Tainá, nove anos de idade, matriculada no $5^{\circ}$ ano do ensino fundamental de uma escola comum de ensino, e Sérgio, oito anos de idade, matriculado no $3^{\circ}$ ano do ensino fundamental de uma escola comum de ensino. Com cada um foram realizadas quatro observações em sala de aula do ensino comum, que ocorreram semanalmente, cada semana em uma disciplina diferente. As observações duraram em média uma hora, visto que acompanhávamos a aplicação de uma atividade com início meio e fim. Em todas as observações foram utilizadas a escala de envolvimento para avaliar o nível de envolvimento dos alunos com deficiência intelectual e a qualidade das interações e mediações realizadas com o mesmo pelos professores.

Antes de entrarmos nos dados propriamente ditos é importante apresentarmos alguns aspectos teóricos. O conceito de mediação que usamos é aquele definido por

${ }^{4}$ Os nomes dos sujeitos são fictícios. 
Vigotski como uma tríade, um processo em que dois elementos necessitam de um terceiro fazendo uma intervenção para se relacionarem, não sendo essa relação direta, mas mediada (VIGOTSKI, 2007). É o que Pino (1991, p. 38) explica como “[...] toda a intervenção de um terceiro 'elemento' que possibilite a interação entre os 'termos' de uma relação". Isto é, em todas as nossas relações a mediação está implícita, possibilitando essa troca de experiências e de conhecimento. Assim como destacado por diferentes estudiosos da perspectiva histórico-cultural, entendemos que o conceito de mediação é central para a compreensão das concepções defendidas por Vigotski (2007) sobre o funcionamento psicológico e o desenvolvimento humano. É no contato com a cultura que vamos nos constituindo e formando saberes. Ou seja, nessa perspectiva, o desenvolvimento humano é caracterizado pela atividade mediada. A inserção da/na cultura é um processo de dupla mediação (dos signos e do outro), que impulsiona o desenvolvimento infantil. Em outros termos, podemos afirmar que toda a relação que estabelecemos com o mundo social e natural é sempre mediada. Essa relação nunca é direta, a mediação é sempre permeada pelos instrumentos, pelos signos e pelo outro que nos constitui, como mencionado anteriormente (PINO, 1991; VIGOTSKI, 2007, 2012).

Nesse sentido, conforme a criança é inserida num determinado contexto cultural, ela vai internalizando/apropriando ativamente as formas de comportamentos já consolidadas na experiência humana, a partir de sua interação com membros de seu grupo e de sua participação em práticas sociais historicamente construídas (REGO, 2014). Contudo, é importante ressaltar que,

[...] a cultura, entretanto, não é pensada por Vigotski como algo pronto, um sistema estático ao qual o indivíduo se submete, mas como uma espécie de "palco de negociações", em que seus membros estão num constante movimento de recriação e reinterpretação de informações, conceitos e significados (OLIVEIRA, 1993, p. 38).

Isso deixa claro o papel ativo que o próprio sujeito possui em seu desenvolvimento.

Outro conceito importante na perspectiva de Vigotski (2012) é a defectologia ${ }^{5}$, na qual o autor defende que o desenvolvimento das crianças com deficiência é semelhante ao desenvolvimento das crianças sem deficiência, com alterações na estrutura que se estabelece no curso de seu desenvolvimento. Para alcançar tal

${ }^{5}$ Ciência que estudava na antiga União Soviética crianças com diferentes tipos de deficiência sob a ótica de várias áreas do conhecimento como a Medicina, Psiquiatria Infantil, Psicologia e Pedagogia. Um estudo cuidadoso sobre a gênese e as implicações desse conceito pode ser vista na tese de doutoramento de Dainêz (2014). 
perspectiva o autor pautou suas investigações e estudos nas leis gerais que orientam o desenvolvimento e o comportamento das crianças sem deficiência para que a partir disso pudesse compreender as peculiaridades apresentadas pela criança com deficiência. Além disso, propôs uma concepção em que as crianças com deficiência precisam ser consideradas como sujeitos singulares, concretos, constituídos e influenciados pelo contexto de relações sociais e de condições materiais em que nasceram e vivem. Nessa direção, retomando a importância das relações sociais em nosso desenvolvimento, esse autor afirma que a escola é o segundo espaço social ao qual teremos acesso durante a vida como um espaço específico para o desenvolvimento.

É na escola que faremos a aquisição dos conhecimentos científicos, os quais nos possibilitarão, consequentemente, o desenvolvimento das funções psicológicas superiores que diferenciam os seres humanos de outros seres vivos. Para Vigotski, Luria e Leontiev (2014, p. 116) “[...] a aprendizagem escolar orienta e estimula processos internos de desenvolvimento". Em outras palavras, na perspectiva histórico-cultural a educação escolar se diferencia da educação não formal pelo fato de o primeiro ser um aprendizado sistematizado e o segundo um aprendizado não sistematizado, o qual ocorre no cotidiano da vida das pessoas (VIGOTSKI, 2007, 2012; VIGOTSKI, LURIA; LEONTIEV, 2014).

Nesse contexto e em concordância com as discussões realizadas até o momento, voltamos a nossa atenção para o processo de aprendizagem e desenvolvimento de sujeitos com deficiência intelectual. Considerando a importância do ensino escolar nos processos de aprendizagem e desenvolvimento desses sujeitos direcionamos a nossa reflexão para o conceito de mediação pedagógica realizada por professores em turmas chamadas "inclusivas".

Lembramos que o conceito de mediação pode ser compreendido de diversas formas, não somente como um momento, imediato e visível, mas, principalmente, como um princípio teórico. Nesse sentido, Smolka e Nogueira (2002, p. 83) são sensatas ao dizerem que “[...] a mediação concebida como princípio teórico possibilita a interpretação das ações humanas como social e semioticamente mediadas, mesmo quando essas ações não implicam a presença visível e a participação imediata de outro". Considerando a mediação pedagógica, assim como Oliveira (2014), entendemos ser fundamental o trabalho planejado com intencionalidade nas ações do professor, as quais interferem efetivamente no processo de aprendizagem do estudante, consequentemente, levando-o ao desenvolvimento. Além disso, nos chama atenção para alguns elementos 
que devem ser considerados na organização do trabalho docente: “[...] os conteúdos (e forma como serão trabalhados), as atividades a serem propostas, a dinâmica do trabalho, a consideração dos conceitos cotidianos e a promoção dos conceitos científicos ou conceituais e análise dos resultados encontrados no trabalho com o estudante" (OLIVEIRA, 2014, p. 149). Sendo assim, a mediação como já mencionado anteriormente não envolve somente uma relação direta entre professor e aluno. Ela está presente também na forma como o professor pensa e organiza sua prática pedagógica, que pode ser inclusiva ou não, dependendo de como planeja as atividades que serão trabalhadas em sala de aula (LIMA, 2017).

De modo geral, a partir das perspectivas que fundamentam nosso artigo, podemos afirmar que o sujeito (nesse caso o professor) por meio dos signos e instrumentos medeia o processo de aprendizagem dos sujeitos com deficiência intelectual que iniciam o processo de internalização dos conceitos passando pelas fases da elaboração conceitual até o momento que conseguem, de fato, se apropriar do conceito científico desenvolvendo concomitantemente as suas funções psicológicas superiores. Mas, como esse processo ocorre em sala de aula? Que caminhos e possibilidades pedagógicas podem ser desenvolvidas para mediar efetivamente as ações docentes em contextos de sala de aula com alunos com deficiência intelectual?

\section{O papel da mediação pedagógica: os casos de Sérgio e Tainá}

Para a análise da mediação pedagógica realizada com os sujeitos de nossa pesquisa elaboramos o quadro a seguir, bem como apresentamos dados das observações realizadas. No quadro evidenciamos a relação da mediação com o nível de envolvimento dos sujeitos de nossa investigação nas atividades propostas. Para tal, usamos como base quatro observações realizadas em sala de aula do ensino comum, cada uma em uma disciplina diferente. Para cada disciplina foi observada uma atividade com início meio e fim, propostas pelas professoras das respectivas turmas de Sérgio e Tainá.

Apresentamos os dados relacionados ao aluno Sérgio. Para ilustrar o seu nível de envolvimento estruturamos o quadro a seguir: 
Quadro 1. Atividades gerais e o nível de envolvimento de Sérgio

\begin{tabular}{|c|c|c|c|c|c|c|c|c|c|c|c|c|c|c|c|c|}
\hline \multirow{4}{*}{ 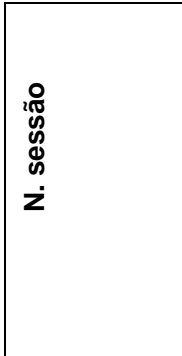 } & \multirow{4}{*}{ Hora } & \multicolumn{5}{|c|}{ Tipo de atividade } & & & & & & & & & & \multirow{4}{*}{ Nível de envol } \\
\hline & & \multirow{2}{*}{\multicolumn{3}{|c|}{$\begin{array}{l}\text { propostas } \\
\text { pela } \\
\text { professora }\end{array}$}} & \multirow{2}{*}{\multicolumn{2}{|c|}{$\begin{array}{l}\text { momentos } \\
\text { de espera } \\
\text { (ind./col) }\end{array}$}} & \multirow{2}{*}{\multicolumn{8}{|c|}{ Áreas de conteúdo/domínio }} & \multirow[t]{2}{*}{ Atividade } & \\
\hline & & & & & & & & & & & & & & & & \\
\hline & & ed & nt & ut & e. e. & ci. & $P$ & AT & d.F & IE & IS & EO & $\mathrm{RT}$ & ut. & & \\
\hline \begin{tabular}{|l|}
$1^{\mathrm{a}}$ \\
$10 / 08 / 15$
\end{tabular} & \begin{tabular}{|l|} 
Inicio \\
11:15h \\
Fim \\
13:15h \\
\end{tabular} & & & & & & & & & & & & & & Composição textual & 2 \\
\hline \begin{tabular}{|l|}
$2^{\mathrm{a}}$ \\
$11 / 08 / 15$
\end{tabular} & $\begin{array}{l}\text { Inicio } \\
11: 15 \mathrm{~h} \\
\text { Fim } \\
\text { 12:15h }\end{array}$ & & & & & & & & & & & & & & $\begin{array}{l}\text { Números cardinais e } \\
\text { ordinais }\end{array}$ & 2 \\
\hline $3^{\text {a }} 01 / 09 / 15$ & \begin{tabular}{|l|} 
Inicio \\
11:15h \\
Fim \\
12:15h
\end{tabular} & & & & & & & & & & & & & & Percursos com obstáculos & 3 \\
\hline $4^{\mathrm{a}} 02 / 09 / 15$ & $\begin{array}{l}\text { Inicio } \\
\text { 13:30h } \\
\text { Fim 15h }\end{array}$ & & & & & & & & & & & & & & As partes da planta & 4 \\
\hline
\end{tabular}




\section{Legenda:}

\begin{tabular}{|l|l|l|}
\hline Tipo de atividade: & \multicolumn{2}{|c|}{ Áreas de conhecimento } \\
\cline { 2 - 3 } Ped. - Atividade pedagógica & LP - Língua & His - História \\
Ent.- Entretenimento & Portuguesa & Ed. F.- Educação Física \\
Out. - Outras & Mat - Matemática & Art. - Artes \\
a.e. - Atividade espontânea & Geo - Geografia & Out - Outras \\
Oci - Ociosa & Cie - Ciências & \\
\hline
\end{tabular}

Fonte: Lima (2017) 
A partir dessas informações e das descrições das atividades contidas na escala de envolvimento de Sérgio verificamos que quanto mais momentos de mediações existentes durante as atividades, maior foi o nível de seu envolvimento com as propostas realizadas pela sua turma. É evidente que compreendemos que o nível de envolvimento nas atividades também está interligado com os conceitos já apropriados pelos sujeitos, assim como pode ser influenciado por várias outras questões como as condições impostas pelo ambiente, a relação do mesmo com os profissionais envolvidos, entre outros. Entretanto, a partir dos dados registrados no diário de campo, podemos afirmar que ao se propor uma mediação pedagógica intencional e planejada maiores foram as possibilidades de aprendizagem e desenvolvimento dos alunos. Os dados mostraram que na atividade de ciências realizada com Sérgio foram contabilizamos 19 momentos de mediações. Nessa tarefa ele atingiu seu maior nível de envolvimento durante toda pesquisa. No inicio da tarefa Sérgio estava disperso e teve dificuldades para se envolver, mas a partir das mediações da professora este cenário mudou completamente.

Outra atividade que analisamos foi proposta na disciplina de Língua Portuguesa. Como mostra o quadro Sérgio teve apenas duas mediações por parte da professora para auxiliá-lo no desenvolvimento desta tarefa. De maneira geral, o tempo de sala era usado pela professora para mediar atitudes comportamentais do aluno, como por exemplo, dificuldades em se concentrar e direcionar a sua atenção para as tarefas de sala de aula. Nesse caso fica evidenciado que o aluno precisa de mediações para desenvolver a atenção e concentração frente às demandas educacionais. Os dados mostram que o principal recurso pedagógico nesse caso era a mediação da professora. Poderíamos aqui dizer que, no caso de Sérgio, este era o principal meio compensatório para que ele conseguisse, de fato, ter um envolvimento com as atividades. Ou seja, quanto mais momentos de mediações pedagógicas com intencionalidade, menos dificuldades Sérgio apresentava e mais envolvimento e engajamento ele tinha com as atividades.

Para ilustrar o caso de Tainá apresentamos uma atividade da área de ciências em que não existiu nenhum momento de mediação. Nesse caso consideramos complexo determinar um nível de envolvimento visto que nenhuma atividade foi direcionada para a participação da aluna. A partir da observação realizada Tainá estava prestando atenção à palestra que estava sendo dada. Mas nenhuma pergunta foi direcionada para ela e não podemos afirmar se estava acompanhando a discussão. Com isso o nível de envolvimento descrito na escala diz respeito somente à aparência do envolvimento da 
aluna, não temos elementos suficientes para mensurar o real envolvimento de Tainá. Vejamos o registro sobre a atividade sem mediação:

A turma recebe a visita de um palestrante. Ele explica que irá falar sobre drogas ilícitas, seus males, violência etc. A maioria da turma demonstra interesse sobre o tema, pois o palestrante consegue prender a atenção de toda a turma, inclusive a de Tainá. Ele pergunta se alguém tem dúvidas. Conforme vai falando sobre o assunto, muitos alunos fazem perguntas e se divertem aprendendo, contudo Tainá permanece sentada e não manifesta interesse em fazer perguntas. Em determinado momento o palestrante pergunta à turma se algum deles mora em região violenta ou em área de risco. Vários levantam a mão. Mesmo morando em área de risco Tainá não levanta. Ao término da palestra ele distribui um livro - que complementa os assuntos que abordou - para cada aluno. Pede que coloquem seus nomes e turma, para explicar o que deveria ser feito com o livro. A professora pede o livro de Tainá para ela e escreve o nome dela no mesmo com letras de forma. Em outro momento o palestrante pergunta à professora se há algum estudante com necessidades especiais, ela diz que sim e mostra Tainá e um menino que é autista. Ele continua a palestra. Não faz perguntas diretamente para Tainá e para o outro aluno com autismo. Quando ele faz mais perguntas para a turma, Tainá presta atenção, porém, continua sem responder (ObEE, 2016).

Como podemos depreender do registro anterior o palestrante não demonstrou uma preocupação que sua palestra fosse entendida por todos os alunos presentes na sala de aula. Tal fato fica evidente no momento em que pergunta à professora se existem alunos com deficiência na turma, mas não apresenta nenhuma proposta de intervenção com os mesmos. Nesse caso era imprescindível que o palestrante tivesse se informado anteriormente sobre as demandas e especificidades de alunos da turma para que todos pudessem compreender e participar ativamente da proposta. Até mesmo na hora da entrega do livro a professora o faz pela Tainá e escreve o nome para ela sem mesmo dialogar com a Tainá. Entendemos a dinâmica complexa de sala de aula. Mas, por outro lado, defendemos que essa seria uma boa oportunidade de a professora trabalhar a escrita de Tainá a partir do seu próprio nome. Corroboramos com Leonel \& Leonardo (2014) quando afirmam que "[...] o trabalho educativo deve buscar superar as limitações a partir do ensino, entendendo a pessoa com deficiência como um ser capaz de desenvolver todo o seu potencial, por meio do acesso aos conhecimentos científicos e das mediações - estas, essenciais para o desenvolvimento da linguagem, do pensamento e da consciência” (p. 543). Agora segue a descrição da atividade de matemática: 
Enquanto a turma copiava expressões numéricas passadas no quadro, a professora trouxe uma folha com atividades para Tainá. Na folha havia o desenho de um bolo e vários numerais "1" para que a aluna cobrisse.

A professora mostrou para Tainá e perguntou: "Quantos bolos tem o menino?". Ela não respondeu. A professora insistiu: "Que número é esse Tainá?". Ela respondeu "2". A professora pediu que ela cobrisse o numeral. Em seguida foi corrigir os cadernos dos demais alunos em sua mesa. A aluna ficou ao nosso lado fazendo da sua maneira a atividade na folha que a professora mandou (ObEE, 2016).

Como podemos perceber existiram várias mediações durante a atividade. Contudo, nenhuma delas foi direcionada para a tentativa de Tainá se apropriar do conteúdo (conceito) que havia sido planejado. A turma fazia outra atividade, expressões numéricas, enquanto isso para Tainá era destinada uma folha para cobrir com o numeral 1. Com esse fato podemos supor que a professora não preparou uma atividade para Tainá referente ao conteúdo de expressões numéricas que estava sendo trabalhado com a turma. Isso evidencia a cultura da descrença sobre as possibilidades de Tainá aprender tão presente na história educacional dessa população.

Tainá, aluna do $5^{\circ}$ ano de escolaridade ainda apresenta enormes fragilidades de apropriação de conceitos matemáticos básicos, mas atividades que podemos considerar descontextualizadas com o que os colegas faziam certamente não são estimulantes para que ela se aproprie desses conhecimentos e avance no seu processo de aprendizagem. Nesse caso deveriam ser planejadas entre professora em colaboração com o professor do AEE e toda a equipe pedagógica, estratégias específicas que propiciassem maior participação da Tainá nas atividades do grupo. Em outros termos, o ideal, neste caso, seria organizar e planejar metas/objetivos a serem atingidos por Tainá a serem realizadas com a mediação da própria professora ou de uma colega. A ideia de tutoria por pares tem se mostrado efetiva no processo de escolarização de alunos com deficiência intelectual como já discutido por Marin e Braun (2013).

Em síntese, assim como no caso de Sérgio, os dados sobre Tainá mostram claramente que quanto mais mediações pedagógicas realizadas, maior foi o seu nível de envolvimento nas atividades escolares. Lembramos que Tainá interagia muito pouco com os colegas de turma e com a professora se mantendo sempre no final da sala. Porém, na aula de artes Tainá foi incentivada pela professora e colegas do grupo para realizar a atividade proposta para toda a turma. Mesmo tendo dificuldades de se dirigir sozinha a um grupo a professora fez a mediação necessária para que ela se inserisse num grupo. O registro sistematiza nossas análises: 
A professora inicia a aula lendo um texto sobre pintura. Tainá ficou sentada em seu lugar, alinhada a turma (em fileiras) roendo as unhas. Após a leitura, a professora anunciou a turma que a aula seria de artes e que deveriam se dividir em grupos para fazer "desenho livre". Disse que iriam se inspirar num desenho ou paisagem retirados de revistas para construírem seus próprios. Os alunos se dividiram livremente.

Tainá foi conduzida pela professora para ficar num grupo, próximo a nós, com alunas "mais tranquilas", segundo a professora. A professora entrega as revistas e pede que Tainá escolha uma figura para desenhar. Tainá escolhe uma figura com predominância de tons em vermelho e marrom. A professora distribuiu os pincéis nos grupos (cada aluno pegava um pincel). Tainá olhava com interesse nos momentos em que a professora parava em seu grupo para dar alguma orientação. As colegas se levantaram para providenciar os materiais e Tainá ficou sentada. Ela começou a pintar com o rosa. A professora coloca o marrom em sua mesa e Tainá troca a tinta pelo marrom, depois volta para o rosa. Uma colega sugere: "Tainá, faz um quadrado pequeno aqui". Tainá sorri, mas ignora a sugestão da colega e continua pintando do seu jeito. A colega mostrou a ela como deveria agir para pintar (molhou o pincel de Tainá na tinta vermelha e passou na folha). As colegas estavam fazendo o desenho por Tainá. A pesquisadora interviu pedindo para que não fizessem por ela, que a ajudassem a fazer sozinha. No momento em que a professora foi atender outro grupo, ela olhou para trás em nossa direção e sorriu e depois voltou a pintar. E desse momento em diante ela pinta o tempo todo. Demonstra satisfação olhando para as colegas e para a professora com esboço de sorriso no rosto. Assim como para nós. Quando a pesquisadora se aproximou do grupo e elogiou os trabalhos, Tainá olhou diretamente para ela e em seguida para os colegas e sorriu, demonstrando satisfação em sua $1^{a}$ produção. Sorria durante grande parte da atividade e tomava iniciativa de limpar os dedos e retomar a pintura. Quando terminou, Tainá levantou-se, foi até a mesa da pesquisadora e mostrou o desenho a ela com sorriso no rosto (ObEE, 2016).

Como podemos depreender, Tainá mostra um grande interesse e satisfação pela atividade proposta. Não desvia a sua atenção da atividade em momento algum e quando acaba o primeiro desenho quer continuar. Sua dificuldade em se expressar fica explícita, mas a professora e a pesquisadora conseguiram mediar esse momento oferecendo outra folha em branco e sugerindo que ela fizesse outro desenho. Tainá conseguiu alcançar o nível 5 de envolvimento e focalizar todas as suas ações para a atividade proposta sem se distrair. Podemos atribuir à atenção direcionada de Tainá às mediações que foram sendo realizadas pela professora e pelas colegas do grupo, formando assim um ambiente que possibilitou à aluna participar e realizar as tarefas solicitadas.

A partir dos dados aqui apresentados fica evidenciado o papel central ocupado pela mediação no processo de escolarização de sujeitos com deficiência intelectual. Corroborando, dessa forma, com os pressupostos da perspectiva histórico-cultural de 
Vigotski que nos embasa na construção de uma escola favorável ao processo de ensino e aprendizagem de sujeitos com deficiência intelectual. Em outras palavras, o que nossa pesquisa evidenciou que as possibilidades de aprendizagem de alunos com deficiência intelectual em turmas comuns de ensino têm sido o caminho para ampliar suas capacidades e o seu desenvolvimento educacional e social. No entanto, faz-se necessário oferecer estratégias e mediações pedagógicas sistematizadas e planejadas para que os alunos com deficiência intelectual não só participem, mas interajam com os colegas e construam conceitos científicos necessários para o seu desenvolvimento social.

Por fim, cabe mencionar que durante toda a pesquisa, assim como nas demais iniciativas deste projeto desenvolvido em rede por grupos sediados em três Programas de Pós-Graduação em Educação de dois estados muito distintos entre si, ficou fortemente marcada a importância da matrícula dos alunos com deficiência intelectual em turmas comuns. Isso só foi possível porque a proposta de educação inclusiva em vigor desde 2008 garantiu direitos que abriram a escola comum a essas pessoas, ampliando as suas oportunidades de inserção educacional e social. Por outro lado, ainda temos que expandir os investimentos em estrutura e recursos pedagógicos das escolas, assim como garantir aos professores salários justos e mais conhecimentos sobre as possibilidades de aprendizagem desses educandos em suas formações iniciais e continuadas. Não se mudam concepções historicamente arraigadas sobre as limitações a priori desses sujeitos do dia para a noite. Isso requer tempo, produção de conhecimento científico e, acima de tudo, organização da sociedade em torno de direitos para todos. Por sua vez, a construção da escola enquanto espaço plural, inclusivo e democrático depende da liberdade de professores e alunos para ensinar e aprender.

\section{REFERÊNCIAS}

\section{BRASIL. Política Nacional de Educação Especial na perspectiva da Educação}

Inclusiva. Brasília, 2008. Disponível em:

http://portal.mec.gov.br/index.php?option=com_docman\&view=download\&alias=1669 0-politica-nacional-de-educacao-especial-na-perspectiva-da-educacao-inclusiva05122014\&Itemid=30192. Acesso em: 10 jul. 2018.

BRASIL. Resolução n ${ }^{\circ}$ 4. Diretrizes Operacionais para o Atendimento Educacional Especializado na Educação Básica, modalidade Educação Especial. Brasília, 2009. 
CAMPOS, E. C. V. Z. Diálogos entre o currículo e o planejamento educacional individualizado (PEI) na escolarização de alunos com deficiência intelectual. 173f. Dissertação (Mestrado em Educação) - Universidade Federal Rural do Rio de Janeiro, 2016.

CATHCART, K. D. P. Crianças com deficiência mental na escola inclusiva: estratégias para aprender. Dissertação (Mestrado em Educação) - Universidade do Vale do Itajaí, 2011.

DAINÊZ, D. Constituição humana, deficiência e educação: problematizando o conceito de compensação na perspectiva histórico-cultural. 132f. Tese (Doutorado em Educação), Universidade Estadual de Campinas, Campis, 2014.

FACCI. M. G. D.; BRANDÃO. S. H. A. A importância da mediação para o desenvolvimento das funções psicológicas superiores de alunos da educação especial: contribuições da psicologia histórico-cultural. XIV Encontro Nacional de Didática e Prática de Ensino (ENDIPE), 30 de abril de 2008, Porto Alegre/RS.

LIMA, M. F. C. O que significa mediar o processo de escolarização de alunos com deficiência intelectual? Dissertação (Mestrado em Educação). Universidade Federal Rural do Rio de Janeiro. 2017.

MARIN, M.; BRAUN, P. Ensino colaborativo como prática de inclusão escolar. In: GLAT, R.; PLETSCH, M. D. (org.). Estratégias educacionais diferenciadas para alunos com necessidades especiais. Editora Eduerj, Rio de Janeiro, 2013, p. 49-64.

MENDES, R. da. S. A escolarização de alunos com deficiência intelectual no ensino fundamental da rede de ensino de Itajaí - SC. Dissertação (Mestrado em Educação) Universidade do Vale do Itajaí, 2016.

MENDES, E. G.; TANNÚS-VALADÃO, G.; MILANESI, J. B. Atendimento educacional especializado para estudante com deficiência intelectual: os diferentes discursos dos professores especializados sobre o que e como ensinar. Revista Linhas. Florianópolis, v. 17, n. 35, p. 45-67, set./dez., 2016.

OLIVEIRA. M. K. de. Vygotsky aprendizado e desenvolvimento um processo sócio histórico. Editora Scipione, 1993.

OLIVEIRA. A. A. S. de. Educação Inclusiva, Educação Especial ou Educação? In: OMOTE, S.; OLIVEIRA, A. A.; CHACON, M. C. M. (orgs.). Ciência e conhecimento em educação especial. Editora M\&M/ ABPEE, São Carlos, 2014, v.1, p. 89-114.

OLIVEIRA, M. C. P. de. A escolarização de alunos com deficiência intelectual a luz da perspectiva histórico-cultural: avaliação mediada e apropriação conceitual. Dissertação (Mestrado em Educação) - Universidade Federal Rural do Rio de Janeiro, 2016.

PADILHA, A. M. L. Desenvolvimento cultural e educação escolar: Aporte teórico para pensar o desenvolvimento psíquico do deficiente intelectual. In: OMOTE, S.; 
OLIVEIRA, A. A.; CHACON, M. C. M. (orgs.). Ciência e conhecimento em educação especial. Editora M\&M/ ABPEE, São Carlos, 2014, v.1, p. 89-114.

PINO. A. O conceito de mediação semiótica em Vygotsky e seu papel na explicação do psiquismo humano. Cadernos Cedes, Campinas, SP, ano XX, n. 24, julho, 1991.

PLETSCH, M. D.; ARAUJO, D. F.; LIMA, M. F. C. Experiências de formação continuada de professores: possibilidades para efetivar a inclusão escolar de alunos com deficiência intelectual. Revista Periferia, v.9, p. 290-311, 2017.

PLETSCH, M. D.; SOUZA, F. F. ; ORLEANS, L. F. . A diferenciação curricular e o desenho universal na aprendizagem como princípios para a inclusão escolar. Revista Educação e Cultura Contemporânea, v. 14, p. 264-281, 2017.

REBELO, A. S. A Educação Especial no Brasil: indicadores educacionais de atendimento especializado (1973-2014). 200 f. Tese (Doutorado em Educação), Universidade Federal de Mato Grosso do Sul, 2016.

REGO, T. C. Vygotsky: uma perspectiva histórico-cultural da educação. 25 Ed. Petrópolis, RJ: Vozes, 2014.

SILVA. C. da. Elaboração conceitual no processo de escolarização de alunos com deficiência intelectual no município de Balneário Camboriú: estratégias e mediações na elaboração de conceitos. (Dissertação de Mestrado) - Universidade do Vale do Itajaí, 2016.

SMOLKA, A. L. B.; NOGUEIRA, A. L. H. O desenvolvimento cultural da criança: mediação, dialogia e (inter) regulação. In: OLIVEIRIA, M. K. de; SOUZA, D, T. R. S.: REGO, C. Psicologia, educação e as temáticas da vida contemporânea. Editora Moderna, São Paulo, 2002.

SOUZA, F. F. de. Políticas de educação inclusiva: análise das condições de desenvolvimento dos alunos com deficiência na instituição escolar. 277f. Tese (Doutorado em Educação). Campinas, 2013.

SOUZA, F. F; DAINEZ. D.; MAGIOLINO. L. L. S. Educação e Desenvolvimento Humano: Modos de Mediação e Participação nos Meandros das Práticas Educacionais Inclusivas. In: PLETSCH, M. D.; MENDES, G. M. L.; HOSTINS, R. C. L. (orgs.). A escolarização de alunos com deficiência intelectual: políticas, práticas e processos cognitivos. Editora M\&M/ ABPEE, São Carlos, 2015, p. 15-30.

VIGOTSKI, L. S. A formação social da mente. NETO, J. C.; BARRETO, L. S. M.; AFECHE, S. C. (Trad). $7^{\circ}$ ed. - São Paulo: Martins Fontes, 2007.

VIGOTSKI, L. S. A construção do pensamento e da linguagem. $2^{\circ}$ ed. São Paulo: Martins Fontes, 2010.

VIGOTSKI, L. S. Obras escogidas V: fundamentos de defectologia (1997). Madrid: Machado, 2012. 
VIGOTSKI, L. S.; LURIA. A. R.; LEONTIEV. A. N. Linguagem, desenvolvimento e aprendizagem. 13 ed. Ícone Editora, São Paulo, 2014.

\section{Como referenciar este artigo}

LIMA, Marcela Francis Costa.; PLETSCH, Marcia Denise. escolarização de alunos com deficiência intelectual sob a vigência da Política Nacional de Educação Especial na Perspectiva da Educação Inclusiva. Revista on line de Política e Gestão Educacional, Araraquara, v. 22, n. esp. 2, p. 872-889 dez., 2018. E-ISSN:1519-9029. DOI: 10.22633/rpge.unesp.v22.nesp2.dez.2018.11918

Submetido em: 30/08/2018

Aprovado em: 20/10/2018 